\title{
Insulating sheath system and energy efficiency of buildings
}

\author{
Ekaterina Bobrova $^{2}$, Anton Pilipenko ${ }^{1, *}$, and Alexey Zhukov ${ }^{1}$ \\ ${ }^{1}$ Moscow State University of Civil Engineering, 129337 Yaroslavskoe shosse, 26, Moscow, Russia \\ ${ }^{2}$ NRU High School of Economics, 101000, Myasnitskaya st., 20, Moscow, Russia
}

\begin{abstract}
The article discusses the results of thermal imaging monitoring of building structures with and without insulation. Research and thermal and physical calculations showed that heat loss from the premises is determined by two groups of factors: surface loss depending on thermal conductivity, as well as vapor and air permeability of enclosing elements and heat loss at all types of joints, fasteners, etc. Thermal insulation with plate materials significantly reduces heat losses, but at the same time, heat flows through the joints between the heat-insulating plates and in the areas of their contact with other structures, necessitating the use of steam and waterproof windproof roll materials. The usage of elastic and thermoplastic materials in the insulation circuit allows minimizing heat loss at the joints between the heat-insulating elements and along the smooth surface of the wall due to the low air and vapor permeability of the material. In the systems of frame cottages, when used as a thermal insulation of rolled foam-polyethylene, it becomes possible to form a seamless insulating shell of a building. This is made possible by connecting individual sheets of polyethylene foam into a lock, followed by hot air welding. Seamless insulation systems are used both in the construction of cottages and in the construction of frame and frameless logistic facilities and housing and communal services.
\end{abstract}

\section{Introduction}

One of the trends in modern construction is the use of composite systems, which, along with prefabricated housing construction, occupy almost equal shares in the construction industry of Russia [1,2].

Modern composite building systems involve the use of effective insulation materials that form the insulating sheath of buildings. Such materials include products based on mineral (stone) wool, foam glass plates, products based on foamed plastics (expanded polystyrene, polyurethane foam, polyisocyanurate foam, polyolefine foam). Products based on stone wool mainly belong to the non-combustible group; foamed plastics are all combustible materials and, depending on the content of fire retardants, can belong to the combustibility groups G2 - G4 [4-6].

\footnotetext{
*Corresponding author: pilipenko.ans@gmail.com
} 
When assessing the thermal efficiency of the insulation contour of a building, such indicators as vapor and air permeability of structures are important. The moisture resistance of materials and the moisture permeability of insulating layers and supporting structures have a significant effect on the long-term eternity of structures. Therefore, in addition to heat-insulating products, steam- and waterproofing materials and wind-proof membranes are used in insulation systems. All these materials are classified as combustible [7, 8].

In a composite building system, insulating, cladding and structural materials, connected either mechanically (dowel-nails, screws, anchors, substructures), or adhesive (on glue, on solutions, etc.) form the insulating shell of the building. The determining factor in the durability of composite construction systems is the joint and maintenance-free operation of all components of such systems.

\section{Materials and methods}

The formation of the insulating shell of a building includes two main factors - minimizing heat loss through the enclosing elements and limiting the air and vapor permeability of the walls.

According to Russian norms SP 50.13330.2012 "Thermal protection of buildings", the enclosing circuit of a building should not "breathe". This function is performed by window, door openings, and forced-air and exhaust ventilation. The use of thermal insulation with low vapor permeability in the construction of walls significantly reduces exfiltration and infiltration, which helps to increase the thermal protection of the system as a whole. The low vapor permeability of such shells minimizes the probability of condensation of water vapor in the thickness of the wall $[9,10]$.

A very significant factor in the preservation of heat in a building, the comfort of the environment in rooms and the preservation of the integrity of structures is the minimization of heat loss through cold bridges and heat-conducting inclusions. The main elements of heat loss are the joints between the insulating plates and between the plates and the wall. Contributions of heat to the heat loss are made by joining the window block to the wall, deformation-shrinkable seams, dish anchors and brackets.

Calculations of the reduced thermal resistance of the facade design based on point-byelement analysis show that in real structures the coefficient of thermal engineering uniformity of the facade is $0.5-0.7$. Heat loss is from 30 to $50 \%$. This necessitates energy monitoring of building construction structures and the development of building systems with the most uniform insulating sheath.

Energy monitoring (thermal imaging using a FLIR E95 thermal imager) was carried out outside the building, which allowed identifying areas of elevated heat loss, areas of possible condensate formation, increased air permeability, hidden defects of construction works (design defects), and errors made in the design.

The studies were carried out in two stages: at the first stage, the thermal imaging survey was carried out back without external insulation (Fig. 1), and at the second stage - with external insulation by facade thermal insulation composite systems (Fig. 2). 

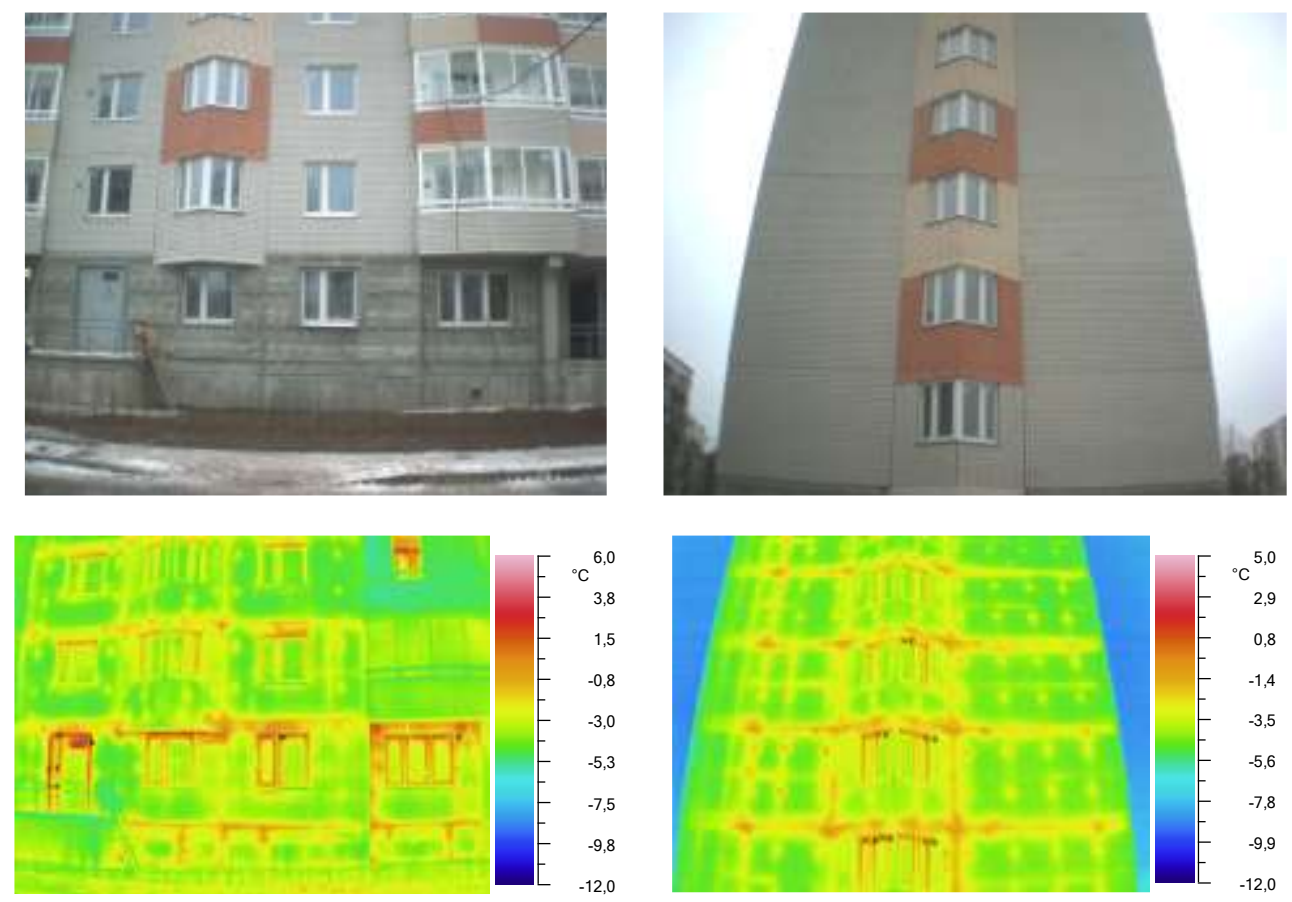

Fig. 1. Thermal imaging of building facades.

\section{Results and discussion}

Thermal insulation photography of block and panel houses (see Fig. 1) showed that the main "bridges" of heat loss are plate joints, window frames, protruding parts of bay windows, elements of engineering systems located close to the outer walls without additional insulation.

Thermal imaging of structures with heat insulation showed: firstly, a significant overall reduction in heat losses; secondly, the formation of cold bridges at the joints of heatinsulating plates and on the adjacencies of these plates to other structural elements. The installation of most types of heat-insulating plate products suggests the formation of one or another joint: which is a cold bridge, as well as unregulated by filtering air or a vapor-air mixture (see Fig. 2).
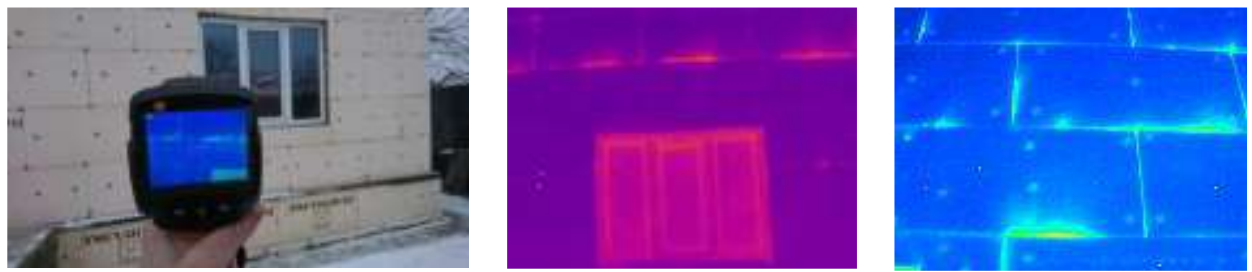

Fig. 2. Thermal insulation of walls with XPS-plates: the "bridges" of heat loss through the joints of the plates and through window and door openings are clearly visible.

When laying the plates in a joint (of any configuration: overlapping into a lock or in a straight joint), the "cold bridge" takes place in any case, but its length is different (Fig. 3). 


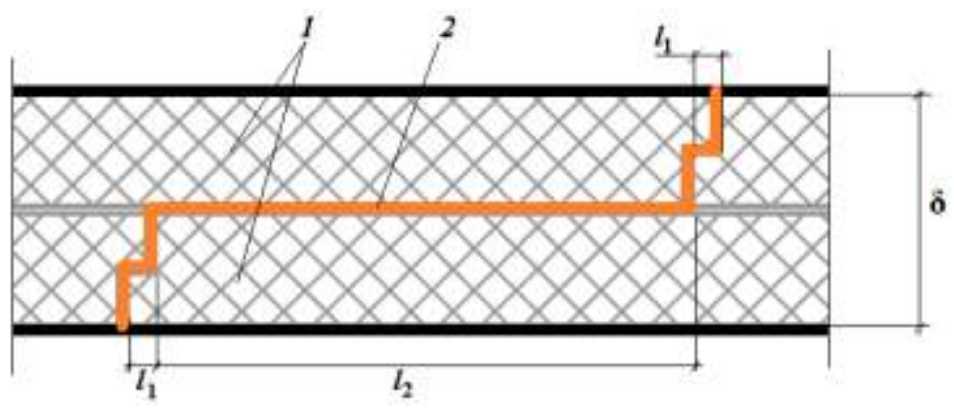

Fig. 3. Scheme of heat loss through the joint of heat-insulating plates: 1 - heat-insulating plates; 2 joint between plates; $1_{1}$ - connection in a quarter, $1_{2}$ - shift with an overlap; $\delta$ is the thickness of the insulation layer.

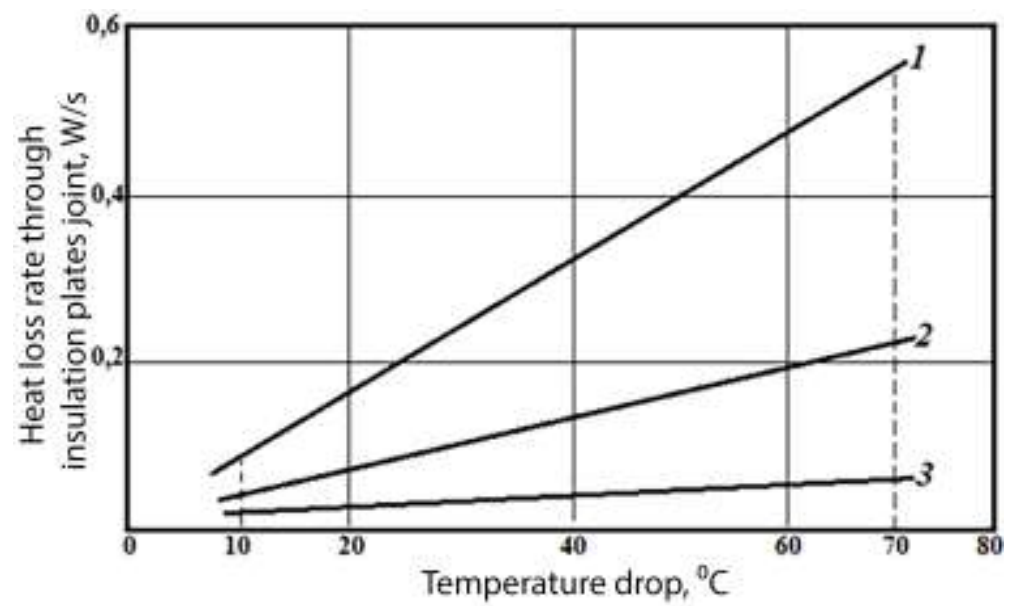

Fig. 4. Minimum heat loss per unit time (W/s) for the joints: 1 - direct; 2 - with milled edge; 3 - with milled edge and overlap ("breakout") of plates.

Calculations and results of in-situ thermal vision monitoring of structures show that the specific heat flux through the joint exists in any case, but its value becomes smaller as a result of a change in the shape of the plate edge or plate shift (Fig. 4). If the flux through the direct joint is taken equal to $\mathrm{q}_{1}$, then the heat flux through the complex interlocking joint with the plate spread will be $(0.50-0.65) \mathrm{q}_{1}$ depending on the thickness of the gaps when the plates fit naturally to each other. Bridges of cold remain regardless of the shape of the joint. Therefore, the only real way to minimize heat loss through the joints and the leakiness of the junction is to form a seamless insulating shell of the building.

The formation of a seamless insulating shell (the task is practically unattainable for plate materials) can be realized with the use of coiled elastic and thermoplastic materials, which include expanded polyethylene, polypropylene and some more gas-filled plastics [9, $11,13]$. The development of welded joint technology [12] has allowed the development of insulation systems for frame and frameless buildings.

In frame systems, heat-insulating materials (as a rule, mineral wool plates with an average density of $50-70 \mathrm{~kg} / \mathrm{m}^{3}$ ) are located between the frame elements and do not perceive the mechanical load. The strength characteristics of such products are low. This implies the protection of the insulation layers not only from mechanical loads, but also from air and vapor-air mixtures. Otherwise, it is possible to carry out fibers and a binder, which 
leads to shrinkage and deformation of heat-insulating products, that is, to the disruption of the integrity of the insulating coating.

The use of polyethylene foam makes it possible to isolate the frame system along the outer contour (Fig. 5). Rolls of unstitched polyethylene (the length of the roll can be made any way according to the technical requirements) are unwound around the perimeter of the building and fixed to the wooden uprights with cap screws. The rolls on the contact surfaces are butt-joint and welded with hot air.

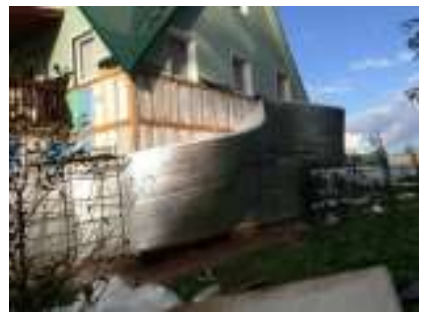

a

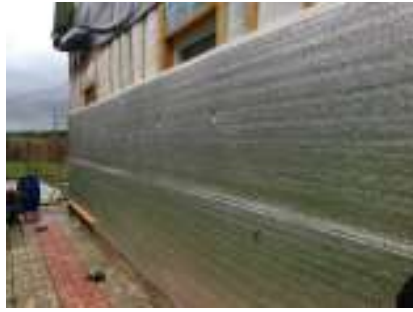

b

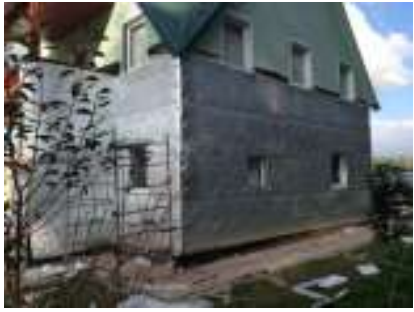

c

Fig. 5. Thermal insulation of the cottage: $a$ - deployment of a roll of unstitched polyethylene; $b$ fixing heat insulation and stitching a roll of unstitched polyethylene; $\mathrm{c}$ - formation of an insulating contour and window openings.

Foam is vapor- and moisture-proof, respectively, and impermeable seamless insulating sheath made of this material. Considering the fact that the insulation shell is located along the outer contour of the frame system, the most important issue is the moisture state of the frame.

\section{Conclusions}

Reducing energy costs in the operation of buildings and improving the comfort of the premises are important issues of modern construction. The monitoring of the constructed objects, taking into account the real heat losses and the real state of the object, is necessary for assessing the existing state of affairs and for forming solutions for the future.

Thermal imaging and elemental thermal and physical calculations show that heat losses in the external insulating circuit of buildings are due to the presence of various types of heat transfer bridges. Thermal insulation with plate materials significantly reduces heat loss, but at the same time, heat flows through the joints between the heat-insulating plates and in the areas of their adhesion to other structures included in the insulation system are preserved.

The use of elastic and thermoplastic materials in the insulation circuit, in particular, rolled polyethylene foam, allows minimizing heat loss at the joints between the heatinsulating elements and along the wall due to the low air and vapor permeability of the material. When performing seamless welded joints of rudder formats, it is possible to form a complex insulating envelope of a building.

\section{References}

1. I.V. Bessonov, A.V. Starostin, V.M. Oskina, Vestnik MGSU 3, 134-139 (2011)

2. V.G. Gagarin, V.V. Kozlov, Academia. Arch. and constr. 2, 60-63 (2006)

3. I.J. Gnip, V.J. Keršulis, S.J. Vaitkus, Mech. of Comp. mat. 41(4), 357-364 (2005)

4. I.J. Gnip, V.J. Keršulis, S.J. Vaitkus, Constr. Mat. 12, 40-44 (2012)

5. V.S. Semenov, T.A. Rozovskaya, A.Yu. Gubsky, Building Materials 6, 21-24 (2016) 
6. A.D. Zhukov, K.A. Ter-Zakaryan, D.U. Tuchaev, E.S. Petrovskij, Int. Agri. J. 1(361), 65-67 (2018)

7. P.M. Zhuk, A.D. Zhukov, Eco. and ind. of Russia. 4, 52 - 57 (2018)

8. A.D. Zhukov, V.S. Semenov, I.J. Gnip, S.J. Vaitkus, Proceedings of the XXVI R-S-P Seminar, Theoretical Foundation of Civil Engineering 117(24), (2017)

9. A.D. Zhukov, B.A. Efimov, Yu.V. Sazonova, A.Yu. Zhukov, Sci. Rev. 7, 10-14 (2017)

10. S.E. Shmelev, Buil. Mat. 3, 7-9 (2013)

11. N.P. Umnyakova, V.M. Tsygankov, V.A. Kuzmin, Hous. Constr. 1-2, 38- 42 (2018)

12. Patent RU2645190 «Lock technology of thermal insulation material for seamless welding of connecting locks» (2018)

13. A.D. Zhukov, K.A. Ter-Zakaryan, A.V. Zayafarov, Ye.S. Petrovsky, D.U. Tuchaev, Roofs and roof mat. 6, 27-29 (2017) 